\title{
Effective Dose Evaluation for Chest and Abdomen X-ray Examinations
}

\author{
Taha M. T. ${ }^{1}$, Kutbi R. A. ${ }^{2}$, Allehyani S. H. ${ }^{3}$ \\ ${ }^{1}$ Physics Department, Faculty of Applied Sciences, Umm Al-Qura University, Makkah, P.O Box 715, Saudi Arabia \\ Radiation Protection Department, Nuclear Research Center, Atomic Energy Authority, Cairo. P.O.13759 Egypt \\ ${ }^{2}$ KingAbduulah Medical Complex \\ ${ }^{3}$ Physics Department, Faculty of Applied Sciences, Umm Al-Qura University, Makkah, P.O Box 715, Saudi Arabia
}

\begin{abstract}
Backqround: The aim of this study was to estimate effective dose (ED) via the indirect measurement of the entrance surface dose (ESD) to patients undergoing chest and abdomen examinations in Hera General Hospital (HGH). Material and Methods: The ESD per examination was calculated from $X$-ray dose output measurements at $80 \mathrm{KV}, 10 \mathrm{mAs}$ and tube output parameters for a patient sample size of thirty eight cases conducted $X$-ray units at HGH. Effective doses (ED) were then estimated using ED/ESD conversion factors based on ICRP-103. Results: Hospital mean ESD for chest posterior anterior was $0.126 \pm 0.027$ mGy and for abdomen anterior posterior was $1.89 \pm 1.14 m G y$. Themean effective doses for chest posterior anterior and abdomen anterior posterior were $0.02 \mathrm{mSv}$ and0.25mSvrespectively. Indirect measurement of ESD is easier than measuring ESD directly for reasons related to patient collaboration. Conclusions: Hospital mean ESD for chest posterior anterior was $0.126 \pm 0.027 \mathrm{mGy}$ and for abdomen anterior posterior was $1.89 \pm 1.14 \mathrm{mGy}$. The mean effective doses for chest posterior anterior and abdomen anterior posterior were $0.02 \mathrm{mSv}$ and $0.25 \mathrm{mSv}$ respectively. Indirect measurement of ESD is easier than measuring ESD directly for reasons related to patient collaboration.
\end{abstract}

Keywords: ESD, ED, ED/ESD conversion factors, Radiology, Indirect, X-ray dose out put

\section{Introduction}

X-ray medical imaging is the largest manmade or artificial source of radiation to the general public and the population $(1,2)$.Dose measurements are required to comply with certain international guidelines and regulations. The International Atomic Energy Agency (3) as well as the European Commission (4) have recommended diagnostic reference levels, (DRL) for radiation dose in medical imaging. DRLs is not a regulatory limit on the dose that can be administered to a patient, it is simply an indicative value. If the dose delivered by an imaging facility consistently exceeds the DRL, it is an indication that the facility should further optimize their scanning protocols. In Saudi Arabia, the National Center for Radiation Protection (SNCRP) in King Abdul-Aziz City for Science and Technology (KACST) is responsible for the optimization of radiation protection and suggesting the best guidance levels for radiation dose in medical imaging.

Entrance skin dose (ESD) is defined as the absorbed dose to air on the X-ray beam axis at the point where the X-ray beam enters the patient or a phantom including the contribution of the backscatter radiation [3].On the other hand, effective dose(ED) is the best quantity for estimating radiation detriment to patients. The major benefit of using the effective dose is that this parameter accounts for the absorbed doses and relative radio sensitivities of the irradiated organs, and therefore, better quantifies the patient risk. However effective dose has the limitation that it cannot be measured directly on a patient, it must instead be calculated. Effective doses are generally calculated from routine dose measurements using conversion factors appropriate to the conditions of the exposure (4). ESD can be measured directly on a patient or inferred from technique parameters and a measurement of the $\mathrm{x}$-ray output under reference conditions. For this reason ESD is the quantity of choice for the optimization of radiation protection of patients in conventional diagnostic radiology examinations. Moreover, assessment of the ESD for patients plays an important role in generating a guidance level for diagnostic X-ray machines (4).Indirect measurement of ESD is easier than measuring the ESD directly for reasons related to patient collaboration, convenience, and the feasibility of using X-ray dose output factors and the operating parameters of the X-ray machine in a reference mathematical equation. Our aim in this study is to perform indirect measurement of the entrance skin dose (ESD) and estimate the effective dose (ED) to patients undergoing chest and abdomen diagnostic Xray examinations in Hera General Hospital, (HGH).The results were compared with established international diagnostic reference levels (DRLs).

\section{Materials and Methods}

The study was conducted at Hera General Hospital (HGH).The ranges of the mean exposure parameters, tube voltage $(\mathrm{kVp})$, current time product (mAs) and focus to skin distance (FSD) at the selected hospital for chest and abdomen examinations are shown in Table 1 . The output of each x-ray unit under reference conditions was determined with a calibrated solid-state detector, Unfors [Mult-O-Meter 407L]. The detector was placed at $100 \mathrm{~cm}$ from the tube focus along the beam axis and the output was measured at $80 \mathrm{kVp}$ and 10 mAs for X-ray machine at HGH. The ESD was calculated using an indirect method. Once the tube potential $(\mathrm{kV})$, the tube current time product (mAs),) and the focus to skin distance (FSD) are known, the ESD can be calculated from equation (1) as discussed by Davies et al(5). 


\section{International Journal of Science and Research (IJSR) \\ ISSN (Online): 2319-7064 \\ Index Copernicus Value (2013): 6.14 | Impact Factor (2014): 5.611}

Table 1: Mean X-ray exposure parameters for posterior anterior (PA) projections of the chest and anterior posterior projections (AP) of the abdomen

\begin{tabular}{|c|c|c|l|l|}
\hline \multicolumn{5}{|c|}{ kVpmAs FSD, cmProjection Examination } \\
\hline Chest & PA & $108-119$ & $1.41-4.15$ & $125-156$ \\
\hline Abdomen & AP & $59-81$ & $1-30$ & $95-158$ \\
\hline
\end{tabular}

$$
E S D=O P \quad\left(\frac{k V p}{80}\right)^{2} \quad m A S \quad\left(\frac{100}{F S D}\right)^{2} \quad B S F(1)
$$

Where (OP) is the output (OP), in $\mu \mathrm{Gy}$ (mAs)-1 of the $\mathrm{X}$ ray tube,$(\mathrm{kV})$ the tube potential, mAs, the product of the tube current in (mA) and the exposure time (ins), FSD, the focus-to-skin distance (in $\mathrm{cm}$ ) and BSF, the backscatter factor.,The IAEA reported that a backscatter factor (BSF) of 1.37 should be used for calculating the ESD for a tube potential of $80 \mathrm{kVp}$, a field size of $30 \times 30 \mathrm{~cm}^{2}$ and a total filtration of $3 \mathrm{~mm} \mathrm{Al}$ equivalent (6). All technique parameters and the BSF were entered in equation (1) to calculate the ESD for each patient to predict the ESD before X-ray imaging. The effective dose is estimated by multiplying the mean ESD by conversion factors, E103/ESD, using equation (2). E103/ESD is the conversion factor reported by Wall et al(7).

$$
E D=E S D \quad E 103 / E S D(2)
$$

\section{Results}

The tube output per mAsof the X-ray machines at $\mathrm{HGH}$ was50.8 $\pm 0.1 \mu \mathrm{Gy} / \mathrm{mAsHalf}$ value layer and radiographic technical data for the modern X-ray unitarepresented in Table 2. Half value layer (HVL) was determined experimentally.

Table 2: X-ray tube outputs, in $\mu \mathrm{Gy}(\mathrm{mAs})^{-1}$ at $80 \mathrm{kVp}$ for $\mathrm{HGH}$

\begin{tabular}{|c|c|c|c|}
\hline Hospital & $\begin{array}{c}\text { Radiographic } \\
\text { unit/model }\end{array}$ & $\begin{array}{c}\text { Half Value } \\
\text { Layer, mm Al eq. }\end{array}$ & $\begin{array}{c}\text { X-ray tube outputs, } \\
\text { in } \mu \mathrm{Gy}(\mathrm{mAs})^{-1}\end{array}$ \\
\hline HGH & GE/XR 650 & 2.9 & $50.8 \pm 0.1$ \\
\hline
\end{tabular}

A total of 38radiographs were included in this study. The proportion of each examination by number of patients was $66 \%$ for chest-PA, $34 \%$ for abdomen-AP. The distribution and mean value of ESD for each examination across all individualadult patients' exposures, calculated according to equation (1), are reported in Table 3. Standard sized patients $(70 \pm 15) \mathrm{kg}$ including chest-PA and abdomen-AP radiographic procedures. Some radiographic such as skull, lumber spin and cervical spin omitted because of missed in Orthopedic doctor.

Table 3: Summary of ESD (mGy) used for effective dose calculations

\begin{tabular}{|c|c|c|c|c|c|}
\hline Projection & Min & Max & Mean & $\begin{array}{c}\text { Standard } \\
\text { Deviation }\end{array}$ & $\begin{array}{c}\text { Max/Min } \\
\text { ratio }\end{array}$ \\
\hline Chest-PA & 0.07 & 0.17 & 0.126 & 0.027 & 2.4 \\
\hline $\begin{array}{c}\text { Abdomen- } \\
\text { AP }\end{array}$ & 0.72 & 2.93 & 1.89 & 1.14 & 5.4 \\
\hline
\end{tabular}

The meanvalues are shown in the Table 3. A comparison between the mean ESD obtained in this work and established international reference dose levels $(3,8,4)$ for each examination is shown in Table 4.
Table 4: Comparison of the hospital mean of the ESDs (mGy) in the present work to some international dose values (in mGy)

\begin{tabular}{|c|c|c|c|c|}
\hline \multicolumn{5}{|c|}{ Organization with DRLs } \\
\hline Projection & This Work & IAEA [3 ] & NRPB [8] & CEC[4] \\
\hline Chest PA & 0.126 & 0.2 & 0.2 & 0.3 \\
\hline Abdomen-AP & 1.14 & 5 & - & - \\
\hline
\end{tabular}

The mean ESDfor chest PA examinations was found to be $0.126 \mathrm{mGy}$ and the mean ESDs for abdomen AP were found to be $1.14 \mathrm{mGy}$ respectively. The effective doses for each type of X-ray examinations were estimated as shown in table 5. An effective dose, $\mathrm{E}$ (given in $\mu \mathrm{Sv}$ ) is calculated by multiplying the mean ESD by conversion factors, E103/ESD with coefficients (9).The comparison of the effective doses for Chest PA and Abdomen AP of X-ray examinations with the international publications (8,9 and 10)were estimated and compared as shown in table 6 .

Table 5: Effective doses (mSv) estimated from ESDs

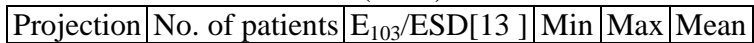

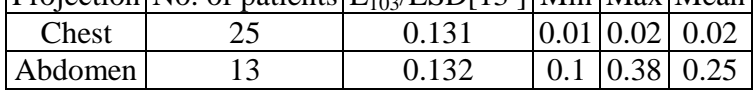

Table 6: Comparison of present hospital mean EDs (mSv) to some international EDs

\begin{tabular}{|c|c|c|c|c|}
\hline & \multicolumn{4}{|c|}{ Mean Effective Dose , mSv, } \\
\hline Projection & Present & Hart et al (9)] & NRPB (8) & $\begin{array}{c}\text { Suliman and } \\
\text { Habbani, (10) }\end{array}$ \\
\hline Chest PA & 0.02 & 0.014 & 0.03 & 0.03 \\
\hline Abdomen AP & 0.25 & 0.43 & 1.36 & - \\
\hline
\end{tabular}

\section{Discussion}

As shown in Table 4 all the ESDs calculated for chest, abdomen were found to be within the corresponding diagnostic reference levels (DRL) recommended by the former National Radiological Protection Board (8)now Public Health England and International Atomic Energy Agency, IAEA (3) and lower than the DRL recommended by the European Commission (4) The variations in ESDs studied may be attributed to factors such as exposure parameters $(\mathrm{kV}$, $\mathrm{mAs}$ ) and FSD. However, the relative low dosage levels found in this study could be attributed to another factor, such as new equipment that was in use. The results are useful to national and professional organization and can be used as a baseline upon which future dose survey could be computed. As shown in table 6 all the EDs calculated for chest and abdomen were found to be within the effective doses calculated by other groups (8-10). The effective dose is the best quantity for estimating radiation risk to patients. The results reflect the necessity of optimizing the parameters for $\mathrm{X}$-ray imaging.

\section{Conclusion}

The indirect method for calculating the ESD assists medical physicists predicting the ESD before X-ray imaging. The indirect entrance skin doses for chest PA, abdomen AP computed for the patients in this study does not exceed the reference diagnostic levels reported by international organizations. The results are useful to national and 
professional organizations and can be used as a baseline for future dose surveys.

\section{Acknowledgements}

This work is supported by grant No. 55-35 from King Abdul-Aziz City for Science and Technology (KACST), Riyadh, KSA. Acknowledgement is due to the Hera General Hospital (HGH) for their assistant and cooperation for complete this research.

\section{References}

[1] United Nation Scientific Committee on the Effects of the Atomic Radiation (2000) Sources and effects of Ionizing radiation Report to the General Assembly Scientific Annex United Nations, New York.

[2] Marie. J,Raolina A.M. Virginia .T. Dose in Simple Radiographic Examinations in Madagascar Initial Results HEP-MAD 9 Antannarivo,.

[3] Madagascar,(2014),8-21-23.3.International Atomic Energy Agency. Optimization of the radiological protection of patients undergoing radiography, fluoroscopy and computed tomography. Final report of a coordinated research project in a Africa, Asia and Eastern. IAEA-TECDOC-. e1423, (2004).

[4] European Committee, EC (1996) .European Guidelines on Quality Criteria for Diagnostic Radiographic Images. UR 16260EN Dose Audit in Diagnostic

[5] Davies M, McCallcum H, White G, Brown J.Helm M. Patient Radiography using Custom Designed Software. Radiography, (1997): 3:17-25.6.IAEA (1996) International Atomic EnergyAgency IAEA Safety Series No.115.

[6] International safety standards for protection against ionizing radiation and for the safety sources.IAEA, Vienna, Austria.

[7] Wall BF, Hillier MC, Haylock R, Hart D, Jansen . (2010)TM, Shrimpton PC (2010) Radiation risks from Medical X-ray examinations as a function of age and sex of the patient. HPA-CRCE.HPA-CRCE Report

[8] NRPB. (1992). National Protocoal for Patient Dose Measurement in Diagnostic Radiology, National Radiological Board http://www.hpa.org.uk/webc/HPA web C/13171401638 77.

[9] Hart D, Hiller MC Wall BF 2007. Does to patients from Radiographic and Fluoroscopic and Fluoroscopic X-ray imaging procedures HPA in the UK-2005 Review.Report, HPA-RPD029.www.hpa.org.uk.

[10] I.I.Suliman and F.I.Habbani. Effective dose calculation in conventional diagnostic X-ray examinations for major Sudanese hospitals.Nagal @R.Magiarvic (Eds) ( IFMBE Proceedings (2003). 